\title{
Phytoremediation of saline dredged sediments: the potential of Arundo donax for chloride phytoextraction
}

\author{
FLORIANE SORDES ${ }^{1}$, SOLÈNE COTHENET ${ }^{2}$, SLIMANE \\ SAHLI $^{2}$, JULIE REGIS ${ }^{1}$ AND ISABELLE TECHER ${ }^{2}$ \\ ${ }^{1}$ Univ. Nîmes, EA 7352 CHROME \\ ${ }^{2}$ Univ. Nîmes, EA 7352 CHROME, rue du Dr Georges Salan, \\ 30021 Nîmes, France
}

Presenting Author: flo.sordes@unimes.fr

Sediments dredging is a technical operation often necessary in harbours in order to maintain boats circulations, servicing and tourist activities. Sediments collected in these dredging have different geochemical quality and some are contaminated either in metal and/or organic components, due to both harbour activities and inland runoffs. The easiest and cheapest way to manage these dredged sediments is often to drop them offshore. But legislation tends to limit this practice that raises numerous debates with regards to environmental impacts. France legislation is getting more restrictive on this issue. The alternative is thus to bring sediments back inland and treat them as waste either for valorisation or elimination. Dredged harbour sediments are initially full of sea water; therefore, chloride levels reduce recycle and elimination possibilities. Management of fine sediments is particularly challenging.

Phytoremediation is one of the technics used to reduce salinity levels. In this way, halophyte species are commonly used to treat salts, through the extraction of $\mathrm{Na}+$ and/or $\mathrm{Cl}$ - ions from soils and waters. Most of the studies dealing with salinity phytoremediation focuses on tropical climate, agriculture or industrial effluents. Few researches have been done on dredged sediments phytoremediation regarding their specific geochemistry and textural properties.

In this study, Arundo donax has been selected as a candidate to phytoremediate chloride from dredged sediments produced in the South of France. These sediments have a clay granulometry and have been naturally dried outdoor for years. Arundo donax is a salt resistant plant naturally present in this region. This species is fast growing and has many commercial uses. This study deals with the choice of this species and its capacity to adapt, grow and extract chloride. Culture experiments were performed under greenhouse and for different modalities, considering addition of arbuscular mycorrhiza and of humic acid. 